\title{
Automated Waste Disposal System in Port Harcourt, Nigeria, Using IOT
}

\author{
Minah-Eeba, Winner'1, Odu, Elendu Victor² \\ 1,2Electrical/Electronics Engineering Department, Port Harcourt Polytechnic, Rivers State, Nigeria \\ Corresponding Author: Minah-Eeba, Winner
}

\begin{abstract}
One of the major problems of most developing towns and metropolises is the degeneration in the state of neatness of the surroundings with respect to waste control. This happens owing to the negligence of the model waste collection method. This negligence produces the spread of waste in communities which in turn generate unhealthy circumstances in the environment. It also stimulates several serious diseases amongst the people in proximity and destroys the beauty of the environment. To avoid negligence of the waste and to increase the neatness of the society, waste monitoring system is needed. In this system, the level of the waste is sensed with the help of ultrasonic sensor and the information is sent to the authorized agency via GSM module. PIR sensor is used to detect the motion of the people coming to the waste bin with refuse when the waste bin is full and stopped adding of more refuse to the bin through sound notification. The GSM and the sensors used are interfaced via the Arduino microcontroller. The receive sms will efficiently help to monitor the waste collection to make the surroundings smart, clean and safe.
\end{abstract}

Keywords: Waste, Arduino, Monitoring, Sensors, GSM Module

\section{INTRODUCTION}

1.1 Background of the Study

It is said that cleanliness is next to godliness. Learn cleanliness from the cat is a proverb used in Ethiopia [1]. The aim of this work is to provide a system that can give decent quality of life and sustainable environment to citizens using microcontroller base solutions. The amount of waste produced and their potential effects rest on various factors: the approach used to manage the wastes, the prevailing state of the immediate environment; the strength (capacity) of the receiving system and the level of industrial advancements.

Everyday piling of solid waste is detrimental to the environment and those that reside in it. It is frequently observed that wastes product are disposed and accumulated around the wastes bins within Port Harcourt city. The wrongly disposed waste became the host for numerous numbers of dangerous micro-organisms, mosquitoes and insects breeding on them. Clean cities does not only imply clean or nice building and parking lots but also include clean environment and automated waste management or disposal system which is a serious problem to be handled in developing cities. Therefore, we need a system that can at least reduce this challenge to some extent. Taking advantage over the improvement in technology we can handle waste management problems properly. The automated waste disposal system is a unique solution to the peculiar and specific issues in waste disposal management. Established waste disposal management system currently deployed in Port Harcourt have fixed route and schedules where wastes from waste bins are evacuated on schedules, from $6 \mathrm{pm}-5 \mathrm{am}$ daily; whether or not they are full and most times resulting to filled waste bins with wastes littered on roads and streets. The sanitation authority in Port Harcourt has tried it best to solve this problem by setting up several waste bin receptacles within the city. This uses manual method and several trucks from the authority are dispatched to collect the wastes and conveyed to designated locations. However, the class of individual involves in assembling and transporting the wastes are in some cases not committed enough to their responsibility. Most times the wastes are not collected and disposed properly. This manual method of managing waste has issues with information about the collecting time and location. There is generally lack of proper system monitoring of the process activities. Citizens also throw waste on open streets and this affects the hygiene of the locality. In order to overcome above mentioned problems, we propose automated waste disposal system using IOT.

Internet of things (IOT) is a growing technology, it enables systems to generate and exchange data. IOT aims at helping human to minimize their efforts [2]. Connected devices (systems) in the network are given a unique identifier (UID). This automated system is implemented using Arduino microcontroller and sensors. Information about each waste bins are monitored by the assigned authority using graphic user interface. The deployment of waste bin monitoring system using microcontrollers, sensors and GSM module make certain the cleaning of the waste bin quickly when the level get to its maximum. 


\section{LITERATURE REVIEW}

In a journal article titled IOT Based Smart Garbage and Waste Collection Bin [3]. They placed a central system to a dustbin with a microcontroller based system containing IR wireless systems and they were able to show current state of waste in a web browser. Their work relied on wifi module which was necessary for their work. Their aim was to minimize human spending and efforts along with the enhancement of a clean city. They could identify when the waste was full, half full and empty. They finalized that the system minimizes trips of wastes collection vehicles and also minimizes spending associated with the waste collection.

In [4], the researched carried out on waste collection in developing countries between 2005-2011 were reviewed and the challenges confronting developing countries in waste gathering were considered. The research investigated the stakeholder's behavior and the evaluation of the influential factors that defined their role in waste gathering processes. The research examined the historical and current practices from 1960 to 2013. The outcome of the research was used to conclude that developing solid waste collection gathering methods in developing countries are very important.

In $[1,4]$ talked about a system developed to concentrate on eliminating ugliness and disorders. The smart trash system uses two sensor namely gas and IR sensor. Gas sensor senses toxic gases while IR sensor senses the level of the waste in the bin. Once the bin is filled, the radio frequency identification placed in the bin gives information about the overflowing bin.

In [4], described some of the major challenges in the urban areas throughout the world regarding waste management. The system uses integrated system combined with Global Position System (GPS), General Packet Radio Services (GPRS) web camera; Radio Frequency Identification (RFID Geographic Information System (GIS). The RFID reader built in the trunk automatically retrieve information about the bin and all customer information from the RFID tag built in each waste bin. The GIS maps server monitors truck movement. GPS gives information about the location of the collecting truck. GPRS communication system was used to update information.

[5] Internet of things (IOT) based intelligent bins for smart cities by Megbana K.C \& Dr. K.R Nataray. They suggested the idea of ultrasonic sensors that will sense the level of the waste bin-full/empty. They used waste bins having three part and three ultrasonic sensors. When the waste crosses the sensed line, the sensor senses the data and the bins are analyzed. The challenge with their design is that the ultrasonic sensor increases cost, the influence of corrosion and vandals.

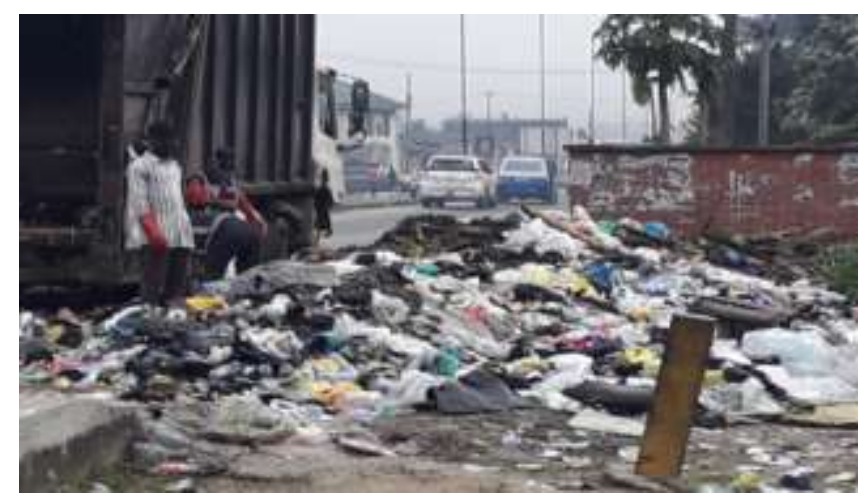

Fig.1: Waste Dump Site at $7 \mathrm{am}$ Thurs $2^{\text {nd }}$ Dec, 2021.

\subsection{Hardware Implementation}

\section{METHODOLOGY}

The automated waste disposal system was realized via the use of a microcontroller (ATmega3289), ultrasonic sensor, power supply. All programmed using arduino uno. 


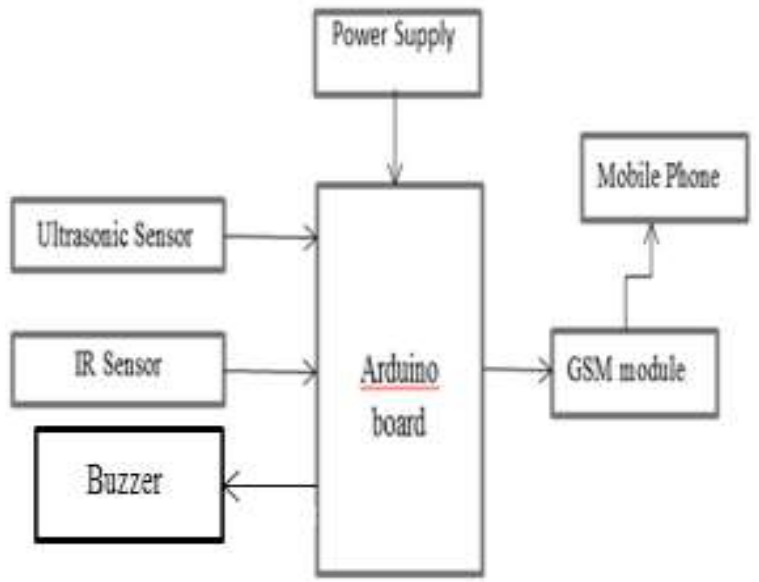

Fig. 2: Block Diagram

\subsection{Hardware}

The required devices were:

GSM module

Arduino board

Ultrasonic sensor

Connecting leads

IR sensor

Bread board

Buzzer

Ultrasonic Sensor- It is a device that can measure the distance of an object or obstacle using sound waves. It is a four pin device/module- Vcc, Trigger, Echo and ground. It contains an ultrasonic transmitter, receiver and control unit. The head of the sensor emit ultrasonic wave and also receive the wave reflected back from the object/target. It is possible to calculate the distance by measuring the time interval between the emission and reception.

Vcc-5v

Trig-5V

Echo-6y

Grid-grid

Distance $=\frac{1}{2} \times \mathrm{T} \times \mathrm{C}$

$\mathrm{T}$ is the time between emission and reception

$\mathrm{C}$ is the ultrasonic speed [6]
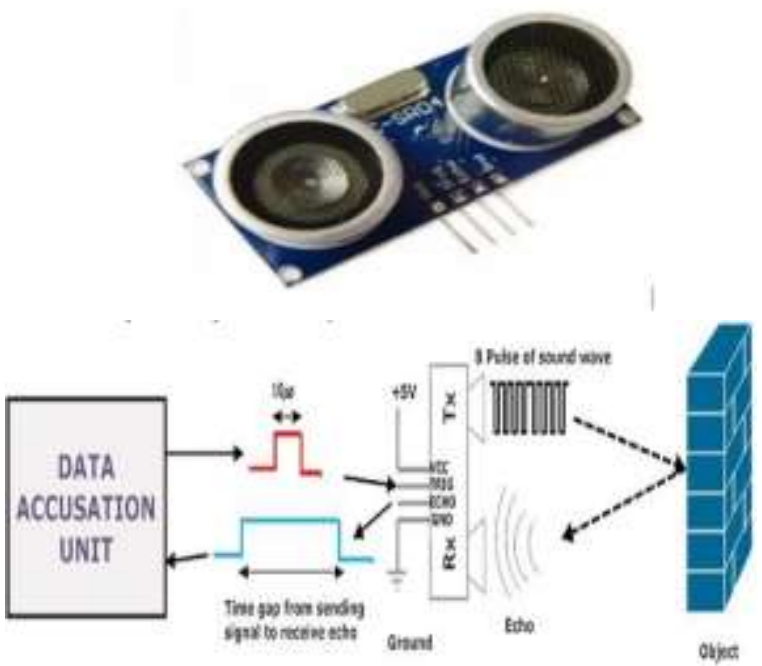

Fig. 3: Ultrasonic Sensor 


\section{Impact Factor $7.39 \because$ Vol. 11, Issue 1, January 2022 \\ DOI 10.17148/IJARCCE.2022.11101}

Arduino Uno- Arduino Uno is an open source platform consisting of a combination of microcontroller, that is, software and a physical programmable circuit board. It is used to write and run program codes and to sync them to the board. Arduino has 14 digital input and output pins, six analog inputs, USB connection, ICSP header, a reset button; a $16 \mathrm{Mhz}$ quartz crystal and a power jack. It has everything needed to assist the micro-controller. It can be powered with a battery, an AC to DC adapter or via a USB cable connected to a computer. A 9v battery can be used to power though the operating voltage is between 7-20volts. [5]

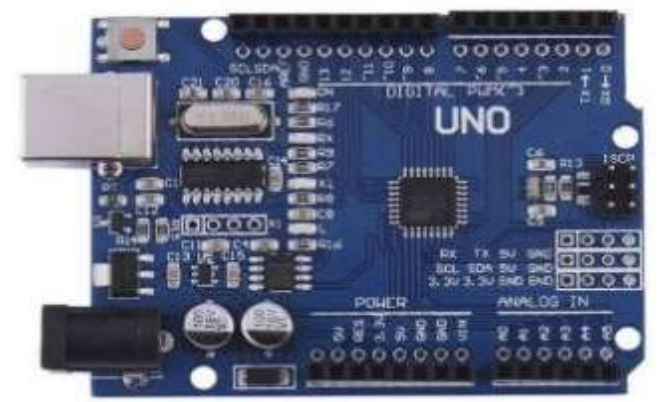

Fig. 4: Arduino Uno R3 Pin Layout

Infrared (IR) - This is an electronic instrument that emits so as to sense certain characteristics of the environment. It achieves this by emitting or detecting infrared radiation. It can detect motion as well as the heat of an object/target. Objects having temperature higher than absolute zero (o Kelvin) possess thermal energy and thus are sources of IR radiation. In addition, objects radiate some form of thermal energy (radiation) in the IR spectrum, and they are invisible to the eyes but are sensed by infrared sensor. Infrared system solves a wide variety of wireless application, especially in sensing and remote controls. Today, DVD players, cell phones, remote control as well as digital cameras use IR for sensing and control. Applying IR with ultrasonic sensor, can eradicate the errors generated by the ultrasonic sensor thus increasing the system accuracy [3]

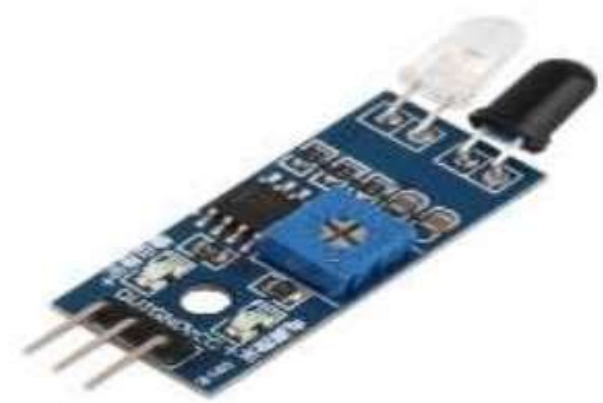

Fig. 5: Infrared (IR)

PIR Sensors- PIR means passive infrared. It allows motions to be sensed. It is called passive because the sensor does not fully participate in the process. It does emit the signals itself but passively detect the infrared radiations coming from the human body in the nearby surrounding. PIR detects when human has moved within the sensor's range. Anytime human body or animals passes, it detects and intercepts the first PIR sensor slot, causing a positive differential change between the two bisects. When the body leaves the sensor's range, the sensor generates a negative differential change between the two bisects. They are easy to connect to a micro-controller. It works as a digital output so we need to listen to know when the pin flips high (detected) or low (not detected). It is powered with a $5 \mathrm{v}$ DC supply and the ground connected to a digital pin. The range is up to 10meters at an angle of $+15^{\circ}$ to $-15^{\circ}$ [5]. Not used in this work but it is an alternative to IR sensor.
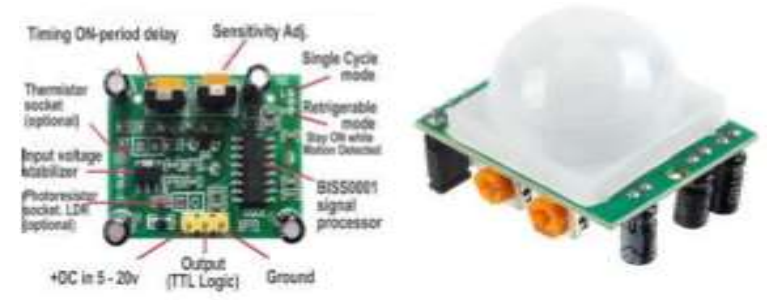

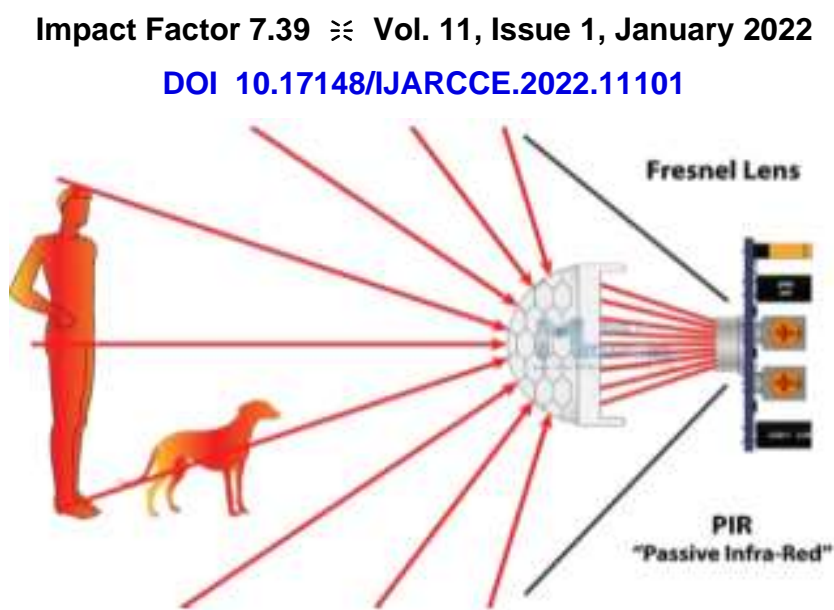

Fig. 6: PIR Sensors

GSM Modem- In GSM system the mobile handset is called the mobile station (MS). A cell is formed by the area covered by a base transceiver station (BTS) which serves the MS in the area covered. Several BTS are controlled by one base station controller (BSC). The BTS and BSC form base station sub system (BSS). The combined traffic from the BS in their various cells is wired via a switch called mobile switching center (MSC). Connection emanating or ending from external telephones are process by a dedicated gateway- Gateway mobile switching center (GMSC).

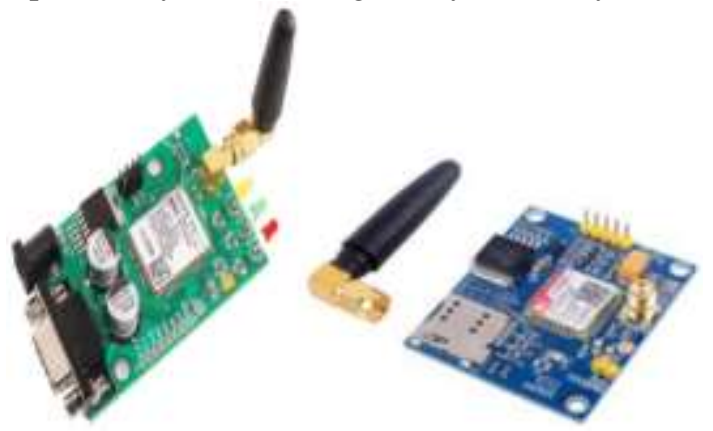

Fig. 7: GSM Modem

\section{Piezzo Buzzer}

It is an active buzzer type which produces a very piercing siren. It has 2 pins underneath it and has a black circuit board to distinguish it from the passive one. It produces a pith of up to $104 \mathrm{~dB}$, a frequency of $2.8 \mathrm{kHz}$ and needs an input voltage ranging from $5 \mathrm{v}$ to $15 \mathrm{v}$. A buzzer or beeper is also an audio signaling device, which may be mechanical, electromechanical, or piezoelectric. Typical uses of buzzers and beepers include timers, alarm devices and some user input device such as a keystroke or mouse click.

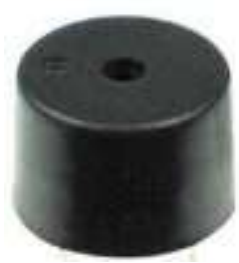

Fig. 8: Piezzo Buzzer

\subsection{Software Implementation}

At the transfer or broadcasting section, the waste level is studied and identified by the level detector-ultrasonic sensor. This analysis is further sent to the microcontroller. When waste in the receptacle reaches the threshold, message is sent to the control room authority in charge through GSM. 


\section{Impact Factor $7.39 \div$ Vol. 11, Issue 1, January 2022}

DOI 10.17148/IJARCCE.2022.11101

\subsection{Flow process}

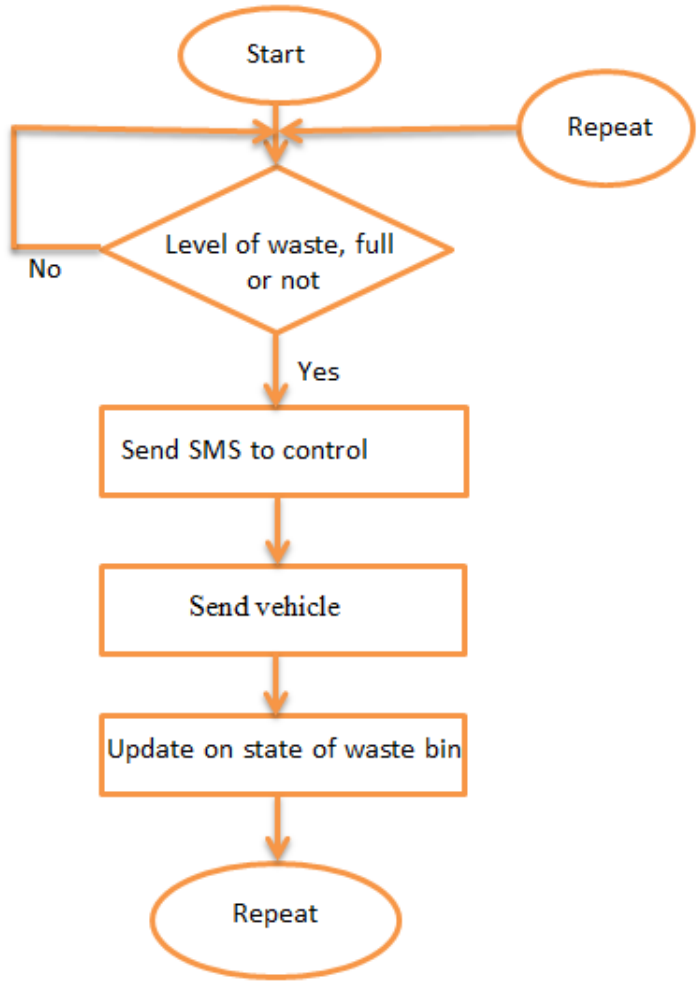

Fig. 9: Flow process

Figure 10 shows the layout module with its pin connection layout. Using the ultrasonic sensor, the VCC, Trig, Echo and GND were connected to its corresponding- 3v3, D1, D2 and GND, in order to access the sensor and apply the code using the Arduino IDE. Since the IR sensor needed a 5v connection, pins D7 and D8 were used to connect to the Arduino Uno R3.

The battery was connected to the voltage source of each microprocessor. D7 and D8 pins of the ESP8266 were connected to the digital pins 3 and 2 of the Arduino Uno R3. The Output pin, VCC and GND of the infrared sensor was connected to the A0, VIN and GND of the Arduino Uno R3. The prototype was placed under the lid of the waste bin as seen in Fig. 8. The prototype read the level of the waste in the bin. Once the waste gets to the expected sense level the sensors will activate.

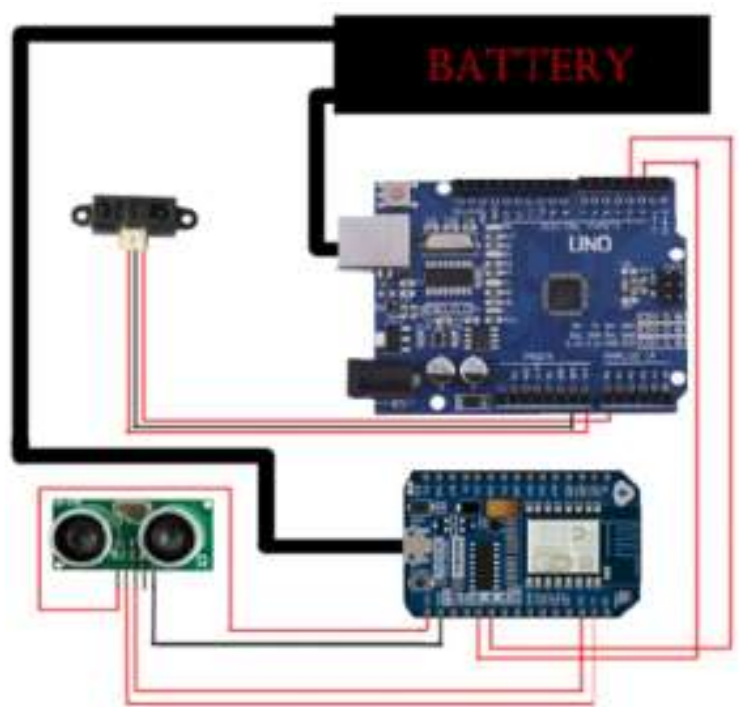

Fig.10: Pictorial Diagram 
DOI 10.17148/IJARCCE.2022.11101

\subsection{Implemented System}

The above Figure 10 depicts the proposed concept been implemented. As observed the system was designed to show us when the trash can is empty or full through the SMS alert. It will be very useful and can be installed in the waste bin at public places as well as at home. To test the system, after uploading the code; open the Serial Monitor and it will show you an IP address.

The IP address was typed into the browser to direct the SMS to municipal authority. If the sensor value read by the Arduino is higher than the threshold value set in the controller the following message is displayed via sms - "Waste bin is full"

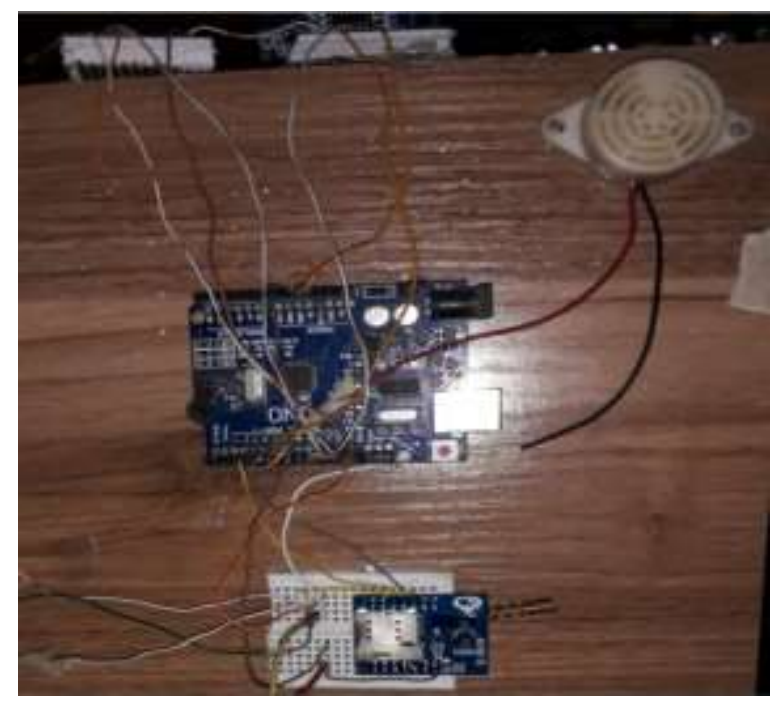

Fig.11: Image of Implemented circuit

\section{RESULTS AND DISCUSSION}

When likened to the expected result, the test run were not inaccurate. The differences between values never exceed 3 centimeters, and both would always fall within the same numerical range. Inaccuracies slowly become more manifest when the distance to the trash increases, which is most likely due to the combined average of the two sensors. However, the accuracy of 75-100 percent approximation was more crucial, since it was within this range that the overflow warning appears. This was where the maintenance staff would usually start being more attentive with the waste content of the bins.

\section{$\mathrm{V}$ CONCLUSION AND RECOMMENDATION}

In this paper an automated waste disposal system for Port Harcourt, Nigeria using IOT was developed to monitor the waste level through the city. The system was very effective in notifying the authorities about the status of the waste at the waste bin location when the status of the waste becomes full. Calculating the level of the waste and notifying the authority about the level of the waste and informing then via sms to collect the trash was the main feature that was developed in the project, making it more dependable and efficient. The motion detection mechanism was done by ultrasonic and IR sensors that make use of infrared waves to locate the presence of an object towards the lid of the waste bin while the bin is full. The interface and software can be improved and revamped according to the requirement of the system for different city authorities with additional research to increase its efficiency and performance. Although the development of the automated system is good, there are things recommended to work on in the future. It is recommended to include camera to the system to capture the image of the environment while the individuals try to dump the waste outside the bin which can be used for penalty, and to add smell and moisture sensors to sense the surrounding and waste bin moisture so that it will be more efficient and user friendly.

\section{REFERENCES}

[1] Fetulhak, A., Sileshi, A; and Chera, A. (2018). “Automated Garbage Monitoring System Using Arduino". IOSR Journal of Computer Engineering (IOSR-JCE) e-ISSN: 2278-0661,p-ISSN: 2278-8727, Volume 20, Issue 1, Ver. I (Jan.- Feb. 2018), pp: 64-76 
[2] Steffy, T W., Tophia, K; and Sebastine, M D. (2019). "Smart trash bin for waste management using odor sensor based on IoT technology". Wilson Steffy Thankam et al.; International Journal of Advance Research, Ideas and Innovations in Technology, Volume 5, Issue 2, pp: 2048-2051

[3] Aaron D M A; and Charleston, F C. U. (2019). "Development of a Cost-Efficient Waste bin Management System with Mobile Monitoring and Tracking”. International Journal of Advanced Trends in Computer Science and Engineering. Volume 8, No.2, pp: 319-327, March - April 2019.

[4] Pranay, M; and Avani, J. (2018). "Implementation of Municipal Solid Liquid Based Smart Waste Management System"- Zero Waste Using Internet of Thing. International Journal of Engineering Sciences \& Research Technology. ISSN: 2277-9655, DOI: 10.5281/zenodo.1345602, value: 3.00, pp: 262-271.

[5] Devansh, J. (2018). "Review of Automated Solid Waste Collection \& Disposable Robot". http: // www.ijesrt.com $\odot$ International Journal of Engineering Sciences \& Research Technology [122] October, 2018, ISSN: 2277-9655; value: 3.00, pp:122-133.

[6] Swati, S; and Sarabjit, S. (2018). "Smart Dustbin Management System". International Journal of Engineering Sciences \& Research Technology. May, 2018, ISSN: 2277-9655; value: 3.00, pp: 169-175.

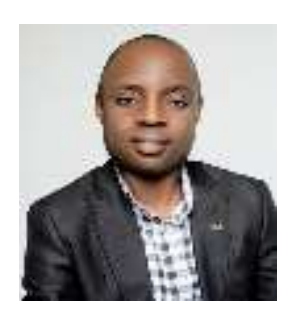

\section{BIOGRAPHY}

Mr Minah-Eeba, Winner is a teaching staff of Electrical/ Electronic Engineering Department, Captain Elechi Amadi Polytechnic, Port Harcourt, Nigeria. His research interests are production operations, instrumentation, Data Commu- nication, Radio wave and optical communication. He completed his HND/B.Eng/M.Tech at Rivers State Polytechnic, University of Port Harcourt and Rivers State University, Nigeria.

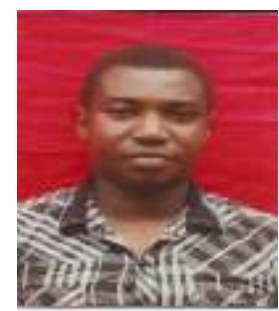

Mr. Odu Elendu Victor is a graduate from the department of Electrical Electronic Engineering of University of Port Harcourt where he obtained a Bachelor in Engineering (B.Eng.). He is an educator with a vast knowledge in repair, design and construction of electronic gadgets, Microcontroller programing and Applications. Currently, he is a teaching staff of Electrical Electronic Engineering Technology, Captain Elechi Amadi Polytechnic, Rumuola, Port Harcourt. 